\section{${ }^{1}$ Dr. Iffat Nowshin Associate Professor Dept. of Community Medicine Shaheed Monsur Ali Medical College, Dhaka \\ ${ }^{2}$ \\ Assistant Professor \\ Dept. of Pharmacology Shaheed Monsur Ali Medical College, Dhaka}

${ }^{3}$ Dr. Md. Iqbal Bahar Chowdhury Assistant Professor Dept. of Forensic Medicine \& Toxicology Shaheed Monsur Ali Medical College, Dhaka

4

Dr. Mahmuda Ahmed Assistant Professor Dept. of Community Medicine East West Medical College, Dhaka

Correspondence

Dr. Iffat Nowshin

Associate Professor

Dept. of Community Medicine

Shaheed Monsur Ali Medical

College, Dhaka

E Mail: drnowshin@yahoo.com

\title{
Role of mass media in disseminating knowledge about Tuberculosis among the attendants accompanying patients of a tertiary care hospital of Bangladesh
}

\author{
I Nowshin ${ }^{1}$, F Alima ${ }^{2}$, M I B Chowdhury ${ }^{3}$, M Ahmed ${ }^{4}$
}

\section{Abstract}

Background : Tuberculosis (TB) is a major public health problem in Bangladesh. The use of mass media is one of the important strategies in communicating behavioural change in relation to TB prevention and the treatment. However, most of the mass media public health interventions do not sufficiently engage the people. Due to this, truly little is known about the effects of locally instigated mass media promotion.

Objective : To explore role of mass media on knowledge generation about Tuberculosis transmission in Bangladesh.

Methods : This cross-sectional study was conducted among 180 adult persons(attendants of patients) of different socio-economic backgrounds attending the outpatient's departments(OPD) of a tertiary care hospital. Purposive sampling was the process of selecting the subjects. Data were collected using one pretested semi-structured questionnaire through face-to-face interview.

Results : A total180 respondents were interviewed. Mean age of the respondents was $28.75 \pm 8.55$ years. Majority of the respondents were graduate $(29.0 \%)$.A total of $20.2 \%$ respondents had adequate knowledge about TB transmission without any misconceptions. Similarly, regarding the misconceptions on modes of TB transmission, $40.5 \%$ replied that TB transmits through utensils, $57.6 \%$ respondents replied that TB transmits through sharing clothes/bed sheets/towel. About 28.3\% respondents had the perception that the cost of TB treatment is high. Among the respondents $30.5 \%$ had the false perception that it was necessary to go to big hospitals for TB treatment. Highest $140(77.8 \%)$ respondents said television as the source of information in TB prevention. Friends/ relatives/ teachers, newspaper, radio, billboard etc. were the other sources. Twenty did not hear of TB prevention program.

Conclusion : The mass media can be effective in getting messages about TB across to the community in developing countries. In this study we found that television, newspapers, and billboards were particularly useful tools for reaching out to them with specific campaigns regarding TB control.

Key words : Mass media, public health, tuberculosis, awareness, urban population.

DOI: https://doi.org/10.3329/nimcj.v11i2.54062

Northern International Medical College Journal Vol. 11 No. 2 January 2020, Page 463-467

\section{Introduction}

In developing countries one of the major public health problem is tuberculosis (TB), affecting nearly one third of world population. ${ }^{1}$ About $80 \%$ of total cases of TB contributes from Asia. ${ }^{2}$ In low and middle income based countries, in every 3 adults 1 die from TB and third leading cause of adult mortality in low- and middleincome countries after the human immune deficiency virus and ischaemic heart disease. ${ }^{3}$ According to World Health Organization (WHO) report, the current prevalence and incidence of TB in Bangladesh is 404 and 227 per 100,000 population per year respectively. ${ }^{4}$ TB is considered as the second greatest killer among infectious diseases after diarrhoea. Poverty and illiteracy, including lack of knowledge and awareness about $\mathrm{TB}$, are major factors responsible for this crucial public health problem. $^{5}$

Directly observed treatment short course (DOTS) is the WHO recommended and promoted 
strategy for treating TB under the supervision of healthcare providers. However, the treatment alone is not sufficient to lower the spread of $\mathrm{TB}^{6}{ }^{6}$ Strategies that influence early case detection and treatment adherence; raising awareness about TB transmission, reducing stigma, misconception, discrimination and delayed TB diagnosis or treatment as well as empowering people affected by TB and establishment of political commitment and resources for TB are important to lower the spread of TB. ${ }^{7}$ Various studies throughout the world have highlighted the importance of knowledge and misconceptions about TB transmission. Examples of misconceptions may include transmission through sharing utensils, by touch, through food, sexual contact or may be mosquito bites. ${ }^{8}$ Less knowledge about TB can contribute to delays in seeking TB care, delayed diagnosis and treatment of active TB cases can endanger populations and communities regarding disease transmission. ${ }^{9}$

Mass media such as television, radio, newspapers, Internet, books, posters, and billboards are widely used for different campaigns to disseminate information to wide range of audiences. Media advocacy involves using mass media in communicating TB-related health information and to raise awareness on TB-related issues and problems. ${ }^{7}$ Mass media interventions have proven effectiveness and efficacy in changing individuals' behaviour towards different health issues ${ }^{10-12}$ and healthcare utilisation given by the Government ${ }^{13}$, reducing stigma about contagious disease ${ }^{14}$ and raising awareness of the signs and symptoms of other diseases. ${ }^{15}$ Moreover the mass media has the capacity to reach and influence every aspect of our life. ${ }^{16}$

As very few studies have been conducted regarding these issues in Bangladesh, therefore much information about the level of knowledge and misconceptions about tuberculosis among our population is not available. Therefore, the present study attempted to identify the prevalence of correct knowledge about tuberculosis disseminated through mass media.

\section{Materials and methods}

This cross-sectional type of study was carried out during January 2019 to June 2019 among the adult attendants of different socio-demographic characteristics accompanying the patients attending OPD of Shaheed Monsur Ali Medical College in Dhaka city. A total 180 respondents of 20-50 years old were selected purposively. After taking informed consent, data were collected by face-to-face interview, using a pretested questionnaire. The knowledge about TB transmission was categorized as-

Correct knowledge if the respondent replied "Yes" to "TB transmits through the air by coughing or sneezing "and vice versa. Misconception if responses about TB transmission were marked "Yes" to the following questions: 1) through sharing utensils 2) through sharing clothes/bed sheets/towel 3) through touching a person withTB 4) through food and 5) through sexual contact.

Collected data was analysed using software SPSS version 20.

\section{Results}

Most of the respondents were in the age group 21-30 years (61.0\%). Mean age was 28.75 years. Out of the total 180 respondent's male were $102(57 \%)$ and female were $78(43 \%)$. A total of $18(10.0 \%)$ were doing govt. service, $36(20 \%)$ private service, 24(13\%) were housewives, 20(11\%) were businessmen, $40(22 \%)$ were students and the rest 42 (24\%) were labourers. Majority of the respondents were graduate $52(29.0 \%), 28(16 \%)$ were having HSC, $34(19.0 \%)$ were SSC and 27 (15\%) were with primary education (Table-I).

Table I : Distribution of respondents according to socio-demographic characteristics $(n=180)$

\begin{tabular}{|llcc|}
\hline Characteristics & Categories & \multicolumn{2}{c}{ Respondent } \\
Age of respondents & & No & Percent \\
& $20-30$ & 110 & 61.00 \\
\hline Sex & $30-40$ & 55 & 30.56 \\
\hline \multirow{2}{*}{ Religion } & $40-50$ & 15 & 8.33 \\
\hline \multirow{3}{*}{ Levels of education of respondents } & Male & 102 & 57.00 \\
& Female & 78 & 43.00 \\
& Primary & 27 & 15.00 \\
& SSC & 34 & 19.00 \\
\hline & HSC & 28 & 16.00 \\
\hline Occupation of respondents & Graduate & 52 & 29.00 \\
\hline & Govt. service & 18 & 10.00 \\
\hline & Private service & 36 & 20.00 \\
\hline & Housewives & 24 & 13.00 \\
\hline & Business & 20 & 11.00 \\
\hline & Students & 40 & 22.00 \\
\hline & Labourers & 42 & 24.00 \\
\hline
\end{tabular}

Among the 180 respondents 170 (95.0\%) watch television and the rest $10(5.0 \%)$ did not watch. Of the total respondents 121 $(67.2 \%)$ read newspaper and rest 59 (32.7\%) did not read. Highest 140 respondents said television as the source of information in TB prevention. Friends/ relatives/ teachers, newspaper, radio, billboard etc. were the other sources. Twenty did not hear of TB prevention program (Fig 1). 


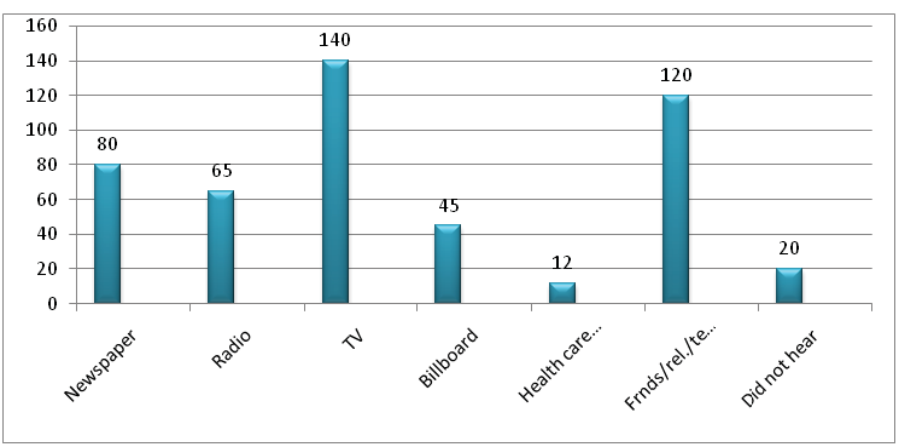

Fig 1: Distribution of the respondents by sources of knowledge on TB prevention (Multiple responses)

A total of $149(83.0 \%)$ respondents correctly replied TB transmits through the air when coughing or sneezing. A total of $36(20.2 \%)$ respondents had adequate knowledge about TB transmission without any misconceptions. Similarly, regarding the misconceptions on modes of TB transmission, 73 (40.5\%) replied that TB transmits through utensils, 104 (57.6\%) respondents replied that TB transmits through sharing clothes/bed sheets/towel, 39 (21.9\%) respondents replied that TB transmits through touching a person with TB, 72 (40.2\%) respondents replied that TB transmits through food and $56(31.1 \%)$ respondents replied that TB transmits through sexual contact.

A total of $50(28.3 \%)$ respondents had the perception that the cost of TB treatment is high. A slightly less than one third [55 $(30.5 \%)]$ of respondents had the false perception that it was necessary to go to big hospitals for TB treatment (Table II).

Table II : Distribution of the respondents by knowledge of TB transmission $(n=180)$

$\begin{array}{lcc}\begin{array}{l}\text { Outcome } \\ \text { Knowledge on TB transmission }\end{array} & \text { Response } & \text { Percentag } \\ \begin{array}{l}\text { TB transmits through the air by coughing or sneezing } \\ \text { Misconceptions }\end{array} & 149 & 83.00 \\ \text { Through sharing utensils (Yes) } & 73 & 40.5 \\ \text { Through sharing cloths/beds sheets/towel (Yes) } & 104 & 57.6 \\ \text { Through touching a person with TB (Yes) } & 39 & 21.9 \\ \text { Though food (Yes) } & 72 & 40.2 \\ \text { Through sexual contact (Yes) } & 56 & 31.1 \\ \text { Cost of TB treatment is high (Yes) } & 50 & 28.3 \\ \text { TB can be cured (Yes) } & 138 & 76.6 \\ \text { Is it necessary to go to big hospital for TB treatment (Yes) } & 55 & 30.5\end{array}$

Regarding Knowledge about Symptoms of Tuberculosis, cough for more than 3 weeks was said by 88 (49\%) respondents, blood in sputum by $58(32 \%)$, loss of appetite by $12(6.9 \%)$ night sweats with fever by $10(5.5 \%)$, weight loss by $50(28 \%)$ and don't know by 22 (12\%) respondents. (Fig-2)

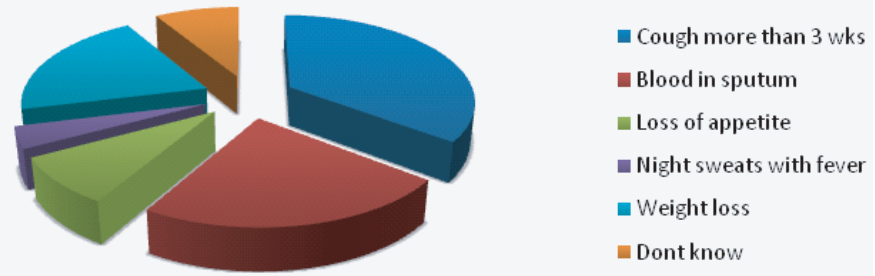

Fig-2 : Distribution of the respondents according to their knowledge regarding symptoms of tuberculosis $(n=180)$

Among the 149 respondents who have correct knowledge about TB transmission $60 \%$ said they watch television almost every day, $16.66 \%$ at least once a week and about $6 \%$ never/less than once a week. Regarding reading newspaper or magazines $49.44 \%$ read every day, $32.22 \%$ at least once a week. They responded also for listening to radio, $30 \%$ listen almost every day, $43.33 \%$ at least once a week and $9.44 \%$ never/less than once a week. (Table III)

Table III : Distribution of respondents according to use of mass media who have knowledge about TB

$\begin{array}{lcc}\text { Category } & \text { Responses } & \text { Percentage } \\ \text { Watches television } & 108 & 60.00 \\ \quad \text { Almost everyday } & 30 & 16.66 \\ \text { At least once a week } & 11 & 6.11 \\ \quad \text { Never/less than once a week } & & \\ \text { Reads newspapers/magazines } & 89 & 49.44 \\ \quad \text { Almost every day } & 58 & 32.22 \\ \text { At least once a week } & 2 & 1.11 \\ \quad \text { Never/less than once a week } & & \\ \text { Listen to the radio } & 54 & 30.00 \\ \text { Almost everyday } & 78 & 43.33 \\ \text { At least once a week } & 17 & 9.44 \\ \text { Never/less than once a week } & \end{array}$

Respondents were asked about sources where they could get treatment if they had TB signs. Among them $26(6 \%)$ said from family doctor,52(12\%) from pulmonologist, $228(54 \%)$ said from hospital, $73(17 \%)$ from DOTS corner and $47(11 \%)$ said they do not know. (Table IV)

Table IV : Distribution of the respondents according to their knowledge on availability of TB treatment

$\begin{array}{lcc}\text { TB treatment availability } & \text { Response } & \text { Percentage } \\ \text { Family doctor } & 26 & 6 \\ \text { Pulmonologist } & 52 & 12 \\ \text { Hospital } & 228 & 54 \\ \text { DOTS centre } & 73 & 17 \\ \text { Do not know } & 47 & 11\end{array}$


Respondents were asked to comment on the role of print media and electronic media on propagation of TB knowledge among the population. Majority 138 (77\%) was in favour of electronic media. Twenty-four (13\%) were saying that our print media is contributing more in knowledge dissemination. Eighteen (10\%) did not deliver any comment. (Fig 3)

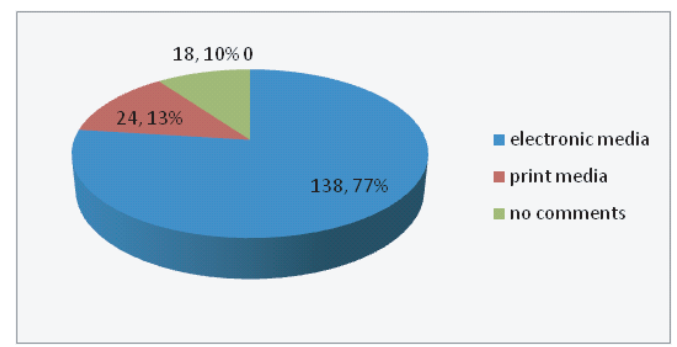

Fig 3: Respondents opinion on comparing print and electronic media on knowledge dissemination about TB

\section{Discussion}

With low levels of awareness about the causes, mode of transmission and preventive methods of tuberculosis the spreading of TB could be high. Several studies done in Ethiopia and Manila explained that most of the respondents heard about TB from television, newspaper, health workers and personal experience for the first time, this study also reported similar findings. ${ }^{16}$ This indicates that for better detection of TB cases mass media, health workers and personal experience were acting as a successful means of disseminating information about TB.

In this study the mean age was 28.75 years with standard deviation of \pm 8.554 of the respondents. The sex ratio is consistent with the sex ratio among adult population of Bangladesh [0.9male(s)/female]. ${ }^{17}$ Majority of the respondents were graduates (29\%). Although Bangladesh has achieved considerable success in TB control in recent years due to the political commitment of the government, ${ }^{18}$ our findings indicate a lack of knowledge about TB transmission among the respondents. Adequate knowledge was observed in only $20.2 \%$ respondents in this study, compared to $22.9 \%$ in Serbia. ${ }^{19}$ Earlier studies in Nigeria, India and Ghana reported poor knowledge of TB transmission among people. ${ }^{22-24}$

It was found that respondents had varying degree of misconception about transmission of TB such as transmission via sharing utensils, via sexual contact, via clothes, bed sheets or towel, via food and via touching a person with TB. High prevalence of misconceptions about transmission of TB was also seen in earlier studies in Pakistan, Ethiopia and India. ${ }^{16} \mathrm{~A}$ study in Ethiopia reported the misconception of sexual intercourse as a cause of TB. ${ }^{20}$ Higher prevalence of misconception about transmission of TB among the respondents might contribute to the stigmatization among people with $\mathrm{TB}^{21}$ Recently in Bangladesh the behavioural change and social mobilization have gained momentum including broadcasting TB/HIV messages through national television, radios, newspapers, TB posters, pamphlets and leaflets to increase case detection, treatment adherence and combating stigma and discrimination related to TB. ${ }^{25}$

This study showed that the frequency of use of media played a significant role in generating correct knowledge on transmission of TB and reading newspapers or magazines and listening to the radio daily enhanced the correct knowledge on transmission of TB. This finding is supported by other studies in Nigeria and India where media had demonstrated most effective contribution to enhance knowledge on $\mathrm{TB}^{26}$ This might be due to higher chance of daily update of health columns. A study in India showed that health messages placed on newspapers and aired in radios were effective in knowledge generating related to TB transmission. ${ }^{27}$ Differing to this, a study in Pakistan showed media such as radios, televisions and newspapers were not the important sources of information about TB or its transmission. ${ }^{28}$

The media (especially television) makes a significant contribution in improving knowledge about TB. The effectiveness of the media in improving notifications, treatment and diagnosis has been reported by other studies in developing countries. For example, In India, prior to an Information, Education and Communication (IEC) campaign, only $10 \%$ of TB patients chose a DOTS centre as their first source of treatment; this proportion rose to $20.4 \%$ after the campaign. ${ }^{27}$

In this study respondents were asked about sources where they could get treatment if they had TB signs. Among them 26 (6\%) said from family doctor, 52(12\%) from pulmonologist, 228 (54\%) said from hospital, 73 (17\%) from DOTS corner and 47 $(11 \%)$ said they do not know. However, it is difficult to evaluate whether the effects of the campaign were long lasting.

Generally, the media is an important source of information and education for the general population and can influence decisions that have a significant impact on the knowledge and understanding of TB disease and control..$^{29}$ Optimal utilization of mass media can play a significant role in the rigorous dissemination of important information and education related to TB and can change the misconception about TB transmission. National TB Control Program in Bangladesh should carry out more frequent dissemination of TB related message through newspapers, magazines and airing of radio programs.

\section{Conclusion}

This study gives an overview of the role of mass media in generating public awareness of tuberculosis. Majority of the 
respondents had knowledge about tuberculosis transmission but very few of them could answer without any misconception. Television was the prime source of information regarding TB, after that newspaper, radio, friends and relatives. Most of them watch television and read newspaper almost every day. But there are so many misconceptions prevailing among the respondents regarding TB transmission and treatment. Therefore, mass media can directly and indirectly produce positive changes or prevent negative changes in health-related behaviours in large populations.

\section{References}

1. Sudre $P$, ten Dam G, Kochi A. Tuberculosis: a global overviewof the situation today. Bull World Health Organ 1992; 70(2): 149-159.

2. World Health Organization. Global tuberculosis report 2013.Geneva: World Health Organization; 2013. [Online] Availablefrom: http://apps.who.int/iris/ bitstream/10665/91355/1/9789241564656_eng.pdf?ua=1 [Accessed on 13rd January, 2018]

3. Lopez $A D$, Mathers CD, Ezzati M, Jamison DT, Murray CJL,editors. Global burden of disease and risk factors. Washington(DC): World Bank; 2006.

4. WHO Global Tuberculosis Report. 2015

5. Khuwaja A K, Mobeen N. Knowledge about tuberculosisamong patients attending family practice clinics in Karachi. JLiaquatUniv Med Health Sci (JLUMHS) 2005; 4: 44-47.

6. Ho MJ. Sociocultural aspects of tuberculosis: a literature review and acase study of immigrant tuberculosis. Soc Sci Med 2004; 59:753-62.

7. World Health Organization (WHO). Advocacy, communication andsocial mobilization (ACSM) for tuberculosis control: a handbook forcountry programmes. Geneva: World Health Organization, 2007.http://www.stoptb.org/assets/documents/resources/publications/acsm/ ACSM_Handbook.pdf (accessed 2 Oct 2018).

8. Vukovic D, Nagorni-Obradovic L, Bjegovic V. Knowledge and misconceptions of tuberculosis in the general populationin Serbia. Eur J Clin Microbiol Infect Dis 2008; 27: 761-767.

9. Mesfi n M M, Tasew T W, Tareke I G, Mulugeta G W M, RichardM J. Community knowledge, attitudes and practices on pulmonarytuberculosis and their choice of treatment supervisorin Tigray, northern Ethiopia. Ethiop ] Health Dev 2005; 19:21-27.

10.Vidanapathirana J, Abramson MJ, Forbes A, et al. Mass mediainterventions for promoting HIV testing. Cochrane Database SystRev 2005;(3):CD004775.

11.Bala MM, Strzeszynski L, Topor-Madry R, et al. Mass mediainterventions for smoking cessation in adults. Cochrane DatabaseSyst Rev 2013;(6):CD004704.

12.Elder RW, Shults RA, Sleet DA, et al. Effectiveness of mass mediacampaigns for reducing drinking and driving and alcohol-involvedcrashes: a systematic review. Am J Prev Med 2004;27:57-65.

13.Grilli R, Ramsay C, Minozzi S. Mass media interventions: effects onhealth services utilisation. Cochrane Database Syst Rev 2002;(1):CD000389.

14.Clement S, Lassman F, Barley $E$, et al. Mass media interventions forreducing mental health-related stigma. Cochrane Database Syst Rev2013;(7): CD009453.
15.Lecouturier J, Rodgers $\mathrm{H}$, Murtagh MJ, et al. Systematic review ofmass media interventions designed to improve public recognition of stroke symptoms, emergency response and early treatment. BMCPublic Health 2010;10:784.

16. Shaila Hossain, Md Mahmudul Haque, Musarrat Haque. Role of Mass Media in Disseminating Knowledge among Urban Population of Bangladesh. JOPSOM, 2012; 31(1-2): 79-88.

17.Auer C, Sarol JJ, Tanner M, Weiss M. Health seeking andperceivedcausesof tuberculosis among patients in Manila. J Trop Med Int Health 2000; 5:648-56.

18.http://www.unicef.org/infobycountry/bangladesh_bangladesh_statistics.html. 20.Kumaresan J A, Ali A K M A, Parkkali L M. Tuberculosis control in Bangladesh: success of the DOTS strategy. Int J TubercLung Dis 1998; 2: 992-998.

19. Vukovic D, Nagorni-Obradovic L, Bjegovic V. Knowledge and misconceptions of tuberculosis in the general populationin Serbia. Eur ] Clin Microbiol Infect Dis 2008; 27: 761-767.

20.Getahun H, Aragaw D. Tuberculosis in rural northwest Ethiopia:community perspective. Ethiop Med J 2001; 39(4): 283-291.

21.Deribew A, Abebe G, Apers L, Jira C, Tesfaye M, Shifa J, et al.Prejudice and misconceptions about tuberculosis and HIV inrural and urban communities in Ethiopia: a challenge for the TB/HIV control program. BMC Pub Health 2010; 10: 400 .

22.Ganapathy S, Thomas BE, Jawahar MS, SelviKJ,Sivasubramaniam, Weiss M. Perceptions of gender andtuberculosis in a south Indian urban community. Indian J Tuberc2008; 55(1): 9-14.

23.Okeibunor JC, Onyeneho NG, Chukwu JN, Post E. Where dotuberculosis patients go for treatment before reporting to DOTSclinics in southern Nigeria? Tanzan Health Res Bull 2007; 9(2):94-101.

24.Dodor EA, Kelly S. 'We are afraid of them': attitudes andbehaviours of community members towards tuberculosis inGhana and implications for TB control efforts. PsycholHealthMed2009; 14(2): 170-179.

25.Ministry of Health and Population. Annual report of Departmentof Health Services. Kathmandu: Ministry of Health andPopulation, Government of Nepal; 2009. [Online] Availablefrom: http://dohs.gov.np/wpcontent/ uploads/2014/04/ Annual_report_2067_68_final.pdf [Accessed on 10th March, 2019]

26.Sharma AK, Sharma R. Impact of mass media on knowledgeabout tuberculosis control among homemakers in Delhi. Int JTuberc Lung Dis 2007; 11(8): 893-897.

27.Sharma AK, Sharma R. Impact of mass media on knowledgeabout tuberculosis control among homemakers in Delhi. Int JTuberc Lung Dis 2007; 11(8): 893-897.

28.Agboatwalla M, Kazi GN, Shah SK, Tariq M. Gender perspectives on knowledge and practices regarding tuberculosis in urban andrural areas in Pakistan. East Mediterr Health J 2003; 9(4): 732-740.

29.Sharma N, Malhotra R, Taneja D K, Saha R, Ingle G K. Awarenessand perception about tuberculosis in the general populationof Delhi. Asia Pac J Public Health 2007; 19: 10-15. 